\title{
Costing methods for combined heat-and-power plants fueled by zero-marginal cost energy sources
}

\author{
Sarah Van Erdeweghe ${ }^{\mathrm{a}, \mathrm{c}}$, Johan Van Bael ${ }^{\mathrm{b}, \mathrm{c}}$, William D'haeseleer ${ }^{\mathrm{a}, \mathrm{c}, *}$ \\ ${ }^{a}$ University of Leuven (KU Leuven), Applied Mechanics and Energy Conversion, Celestijnenlaan 300 - box 2421, \\ B-3001 Leuven, Belgium \\ ${ }^{b}$ Flemish Institute for Technological Research (VITO), Boeretang 200, B-2400 Mol, Belgium \\ ${ }^{c}$ EnergyVille, Thor Park 8310, B-3600 Genk, Belgium
}

\begin{abstract}
In this paper, several cost metrics for application to a combined heat-and-power plant fueled by a zero-marginal cost energy source are studied. The mature levelized cost concepts are extended with some novel metrics such as the levelized cost of exergy. The results are given for a geothermal combined heat-and-power plant, connected to two different types of district heating systems and for two scenarios for the heat and electricity prices (high and low). For a low price scenario, the conventional costing method based on two separate prices for electrical and thermal energy is the most appropriate. Also for a high price scenario, the conventional costing method is the most appropriate for heat demands at low temperature. However, for higher-temperature heat demands, the exergy costing method results in the highest revenues for the combined heat-and-power plant. The authors recommend the use of the novel levelized cost of exergy metric as different types of energy are priced with a single value. Depending on the amount of energy and the usefulness of the energy type, an appropriate cost can be allocated to each product of a multi-energy system.
\end{abstract}

Keywords: renewable energy, thermoeconomic optimization, CHP, levelized cost, costing methods, low-temperature geothermal energy

${ }^{*}$ Corresponding author
Email address: william.dhaeseleer@kuleuven.be (William D'haeseleer)

Preprint submitted to Energy Conversion and Management

March 4, 2019 


\section{Introduction}

Several cost metrics exist to indicate the economic performance of an electrical power plant. Among others, the net present value (NPV), the levelized cost of electricity (LCOE) and the specific investment cost (SIC) are mature concepts. The NPV gives the economic attractiveness of a project, taking into account the investment costs, the operating and fuel costs, and the revenues from selling electricity over the entire lifetime. The LCOE is the price for electricity that is required over the entire lifetime to break even at the end of the project's life, and the SIC is the ratio of the investment costs and the electrical power output.

These economic metrics are also frequently used in the literature for stand-alone electrical power plants fueled by geothermal energy [1,6]. Fiaschi et al. [1] performed an exergoeconomic analysis for a geothermal organic Rankine cycle (ORC) and Kalina cycle. They considered two types of geothermal energy sources; one at a low temperature of $120^{\circ} \mathrm{C}$ and one at a medium temperature of $212^{\circ} \mathrm{C}$. For the low-temperature source, the Kalina cycle has an electricity cost of 125EUR/MWh, which is 24-34\% lower than for the ORC. However for the medium-temperature energy source, the ORC shows better performance with an electricity cost of 88.5EUR/MWh. Aali et al. 2] performed a thermoeconomic optimization of a combined flash-binary geothermal plant. From the single-objective optimization towards minimal specific cost of output power, they found that the cycle with R141b as working fluid has the best performance with 4.901USD/GJ. For the Pareto front optimization considering the exergy efficiency and the specific cost of output power, the optimal point is at 54.87\% exergy efficiency and 5.068USD/GJ. Walraven et al. 3 optimized the design of water- and air-cooled geothermal ORCs towards minimal LCOE. They concluded that the LCOE for the water-cooled ORC is lower due to the higher net electrical power output and the lower investment costs. However, if no water is available or the water price is very high $\left(>1 E U R / m^{3}\right)$, the air-cooled ORC becomes better. An LCOE in the range of 60-170EUR/MWh and 55-140EUR/MWh has been found for the air-cooled and the water-cooled geothermal ORC, respectively, considering a decreasing brine temperature from $150^{\circ} \mathrm{C}$ to $100^{\circ} \mathrm{C}$. Usman et al. [4] compared an air-cooled and water-cooled geothermal ORC during off-design for different geographical locations. The optimization objective during off-design is the net electrical power output. They made an economic comparison based on the SIC and the LCOE (considering the ORC only) and concluded that cooling tower based systems are preferable for hot dry regions, whereas in mild 
climates, air-cooling can be applied. Budisulistyo et al. [5] presented a lifetime design strategy for binary geothermal power plants, taking into account the resource degradation. For the investigated power plant, they found that the design for a partly degraded geothermal energy source at year 7 has the highest overall NPV. Furthermore, they suggested some measures to overcome lower net power output due to resource degradation. On the one hand, structural changes can be made by installing a recuperator and reducing the heat transfer areas of the vaporizer and condenser at half-life. On the other hand, the mass flow rates of the working fluid and the air cooling can be adjusted to keep reasonable performance over the lifetime. Yilmaz [6] compared three exergoeconomic methods for application to the Dora II binary geothermal power plant in Turkey. The specific exergy costing method, the modified productive structure analysis and the unit system of one product method have been compared for this application. The last method can only be applied for a system with one product, whereas the other two methods are applicable for plants with more than one product. Yilmaz found electricity production costs in the range of 35.5-43.6USD/MWh, depending on the method.

Also different (near) zero-marginal cost renewable energy sources have been studied for electrical power production $7+12$. Clauser et al. 7] compared the levelized cost of electricity for different types of conventional and renewable energy sources. They concluded that geothermal power plants have an LCOE which is highly competitive with conventional energy sources for regions with natural steam reservoirs. In other regions, geothermal power production might be competitive if engineered geothermal systems (EGS) would become a mature technology. However, more funding for EGS research and for lowering the upfront risks and investment costs are required to achieve this. Tran et al. 8] compared the LCOE for power plants with different conventional and renewable energy sources under uncertainty of capital costs, O\&M costs, system reliability and economic factors. The authors concluded that the fossil fuel-based technologies have the lowest LCOE values but nuclear, hydropower, biomass and geothermal are also very competitive energy sources. Furthermore, they found that the addition of carbon pricing shifts the competitiveness of the different technologies, with a negative impact on the fossil fuel-fired systems. Braimakis et al. 9] performed a thermoeconomic optimization for different energy source conditions $\left(100^{\circ} \mathrm{C}\right.$ to $300^{\circ} \mathrm{C}$, presenting multiple renewable energy sources) and used the SIC as the economic metric. They found that the SIC is very variable, from $15,067 \mathrm{EUR} / \mathrm{kWe}$ (source temperature of $100^{\circ} \mathrm{C}, 1.41 \mathrm{kWe}$ ) to $770 \mathrm{EUR} / \mathrm{kWe}$ (source temperature of $300^{\circ} \mathrm{C}, 110.58 \mathrm{kWe}$ ). Zhang et al. [10, Tian et al. 11] and Xi et al. [12, used 
the LCOE as the economic metric in their thermoeconomic analyses. Zhang et al. [10] compared different types of heat exchangers for a waste heat source of $120-200^{\circ} \mathrm{C}$. They found LCOE values in the range of 55 to 70USD/MWh for the optimal shell and finned tube type heat exchangers. Tian et al. 11] studied different zeotropic mixtures for application in a dual-loop ORC for diesel engine waste heat recovery. They concluded that an optimal LCOE of $60.3 \mathrm{USD} / \mathrm{MWh}$ can be achieved for a MD2M/R123 (0.35/0.65) mixture. In addition, Xi et al. [12] investigated mixtures with R245fa (as flame retardant) for waste heat temperatures of $100-180^{\circ} \mathrm{C}$. They found that the use of mixtures is more economic than using a pure working fluid, mainly due to the lower evaporator investment cost. The mixtures R245fa/isopentane and R245fa/pentane were recommended.

Application of the LCOE and SIC concepts is very straightforward for a stand-alone electrical power plant since there is only one product. Similarly, for a stand-alone heating plant, the NPV, the SIC and the levelized cost of heating $(\mathrm{LCOH})$ can be defined. For example, in the paper of Dominković et al. [13, the share of each technology in the heat production mix to a district heating (DH) system is defined based on the marginal cost of each technology. In that study, the authors have shown that the use of waste heat and solar energy — which have (near) zero fuel costs — leads to lower marginal costs. Besides, Huculak et al. [14 and Kecebas et al. 15 have used the LCOH as the economic metric for geothermal DH systems. Huculak et al. 14 studied the economic aspects of six geothermal heating plants in Poland. They compared the net price of $1 \mathrm{GJ}$ for different fuel types and concluded that the use of brown coal is the cheapest, followed by black coal. The authors found that geothermal systems are less competitive but have a lower LCOH than natural gas, biomass and fuel oil. The drawbacks of geothermal systems are the high risks and start-up costs. Kecebas [15] performed a comprehensive analysis of the Afyon geothermal DH system in Turkey, using seven wells with a reservoir temperature of $\sim 105^{\circ} \mathrm{C}$. Kecebas concluded that geothermal energy is cleaner and cheaper $\left(0.397 \mathrm{USD} / \mathrm{m}^{3}\right)$ than fossil fuel-fired systems.

The allocation of costs and revenues becomes more difficult for an energy production system with multiple products. While there are straightforward methods for the stand-alone heating and electricity plants, this is no longer the case for a multi-energy system. Some papers have used the exergy costing method for the assessment of multi-energy generation system [16 19, others have used the equipment cost technique (per module) [19 21]. Mehrpooya et al. [16] investigated a solar fueled regenerative two-stage ORC with storage tank, and used LNG to cool the condenser. Chilled water 
is produced via the cold LNG and additional electrical power is generated by expanding the LNG over a turbine. The optimal point of the Pareto front considering exergy efficiency and product cost rate is at $19.59 \%$ and $3.8810^{6} \mathrm{USD} /$ year. Akrami et al. [17] studied a geothermal system providing electricity, heating, cooling and hydrogen. For a geothermal water temperature of $185^{\circ} \mathrm{C}$ and $215^{\circ} \mathrm{C}$, the total unit cost of the products are $23.18 \mathrm{USD} / \mathrm{GJ}$ and $22.73 \mathrm{USD} / \mathrm{GJ}$, respectively. Boyaghchi et al. 18 have also studied a geothermal $\left(133^{\circ} \mathrm{C}\right)$ multi-generation system which provides electricity, heat for vaporizing LNG, cooling and hydrogen. They found that by optimizing some operating conditions, the total avoidable exergy destruction cost rate can be improved by a factor 4.9

Karellas et al. 20 considered a hybrid biomass and solar trigeneration system. They concluded that for providing heating, cooling and electricity to a typical Greek apartement block, the savings in fuel oil and electricity consumption lead to an internal rate of return (IRR) around $12 \%$ and a payback time of 7 years. Pina et al. 21] proposed a cost allocation method for the products of a hybrid solar and natural gas-fired trigeneration system with thermal storage tank. They assumed that all input energy flows (natural gas, solar radiation and electricity) and their respective costs are known. Based on these input values, they found a cost allocation method which results in total annual savings of 9,942EUR. And finally, Leiva-Illanes et al. [19] investigated a quadruple solar energy system and have compared the bare equipment cost technique with the levelized exergy costing method. The authors concluded that the exergy costing method is more accurate, whereas the equipment cost method can be used for a quick calculation of some levelized cost indicators. They calculated the levelized electricity, heating, cooling or water cost (LEC, LHC, LCC and LWC respectively ${ }_{1}^{1}$ for every individual module. However, no general levelized cost metric for the entire multi-energy system has been proposed.

Also for the investigation of combined heat-and-power (CHP) plants, it seems that there is not one outspoken cost metric to be used. For example, Mundada et al. 22, studied the economic performance of a system consisting of off-grid solar PV panels, combined with batteries and a natural gas CHP for domestic applications. They allocated all costs to the electricity generation

\footnotetext{
${ }^{1}$ The LEC in the work of Leiva-Illanes et al. 19 is the same as the levelized cost of electricity (LCOE) in this paper. The LHC, LCC and LWC are defined in an analogous way.
} 
part and therefore used the LCOE as the performance indicator. Furthermore, the NPV, the IRR and the annual profits have been used by Pantaleo et al. 23 and Martelli et al. 24 for a hybrid solar biomass and a pure biomass CHP system, respectively. The advantage of the NPV and related concepts is that the costs and revenues related to all components, fuels and products are caught within one clear cost metric. From these cost metrics, it can directly be derived whether the project is profitable or not. In the work of Noussan [25], different cost allocation methods are proposed for natural gas-fired CHP systems. Allocations based on energy, exergy, separate generation and weighted energy prices are proposed, and even special allocation methods called "power" or "heat" bonus are discussed. However, the proposed cost allocations are based on the primary energy/fuel consumption, which is less appropriate for (near) zero-marginal cost waste heat or renewable energy sources like geothermal ${ }^{2}$

In this paper, some existing and novel cost concepts for application to CHP plants fueled by a (near) zero-marginal cost renewable energy source will be discussed. The existing levelized cost metrics will be extended with some novel metrics, such as the levelized cost of exergy (LCOEx), which properly accounts for the two products in one levelized cost metric. The different cost metrics will then be applied to a CHP plant which is fueled by low-temperature geothermal energy, and which delivers heat to a DH system and an ORC in parallel.

The novelty of this paper is that different levelized cost metrics, specific investment cost definitions and costing methods are defined and compared for a CHP plant, which is fueled by a (near) zero-marginal cost energy source. In contrast to the conventional fossil fuel-fired systems 25, the proposed metrics are not based on the fuel consumption/price since the operating fuel costs are zero or can not be clearly allocated for these types of energy sources. Furthermore, also the levelized cost of exergy concept for application to a CHP plant is novel compared to the existing literature.

\footnotetext{
${ }^{2}$ For most of the renewable energy sources, the fuel price can not be directly allocated to the energy source (which is in contrast to e.g., gas-fired systems). For example, in case of geothermal, once the well drillings are made, the geothermal energy source is continuously available. Note however that the pumping power costs might be considered as operating/fuel costs in this case.
} 


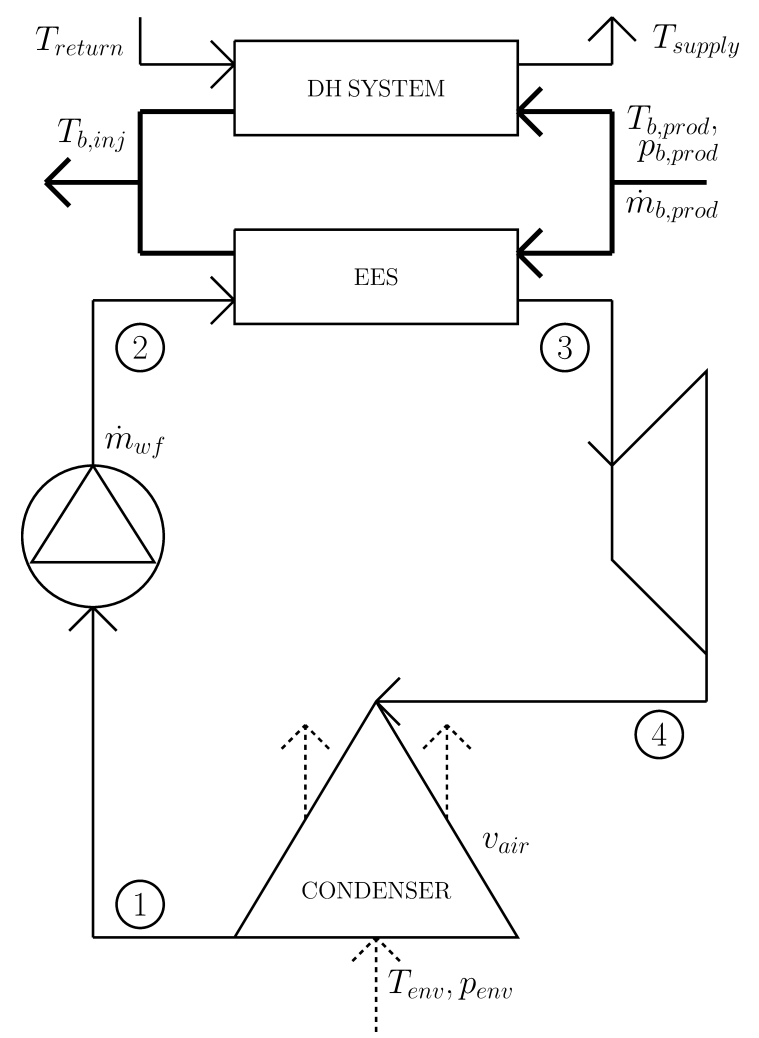

Figure 1: Set-up of the parallel CHP configuration, fueled by low-temperature geothermal energy. The bold lines indicate the path of the geothermal fluid (also called brine). EES stands for the combination of economizer, evaporator and superheater.

\section{Parallel geothermal combined heat-and-power plant}

In this section, the CHP set-up, the reference parameter values and the ORC working fluid are discussed.

\subsection{Set-up}

Fig. 1 shows the set-up of the geothermal CHP plant. The geothermal fluid (also called brine) delivers heat to an ORC for electricity production and to a DH system in parallel. The brine, which is indicated by the bold lines, is pumped from a production well and is pumped back in the injection well after utilization. The connection to the DH system, with supply and return temperatures given 


\begin{tabular}{c|c|c|c|c} 
Brine \& wells & Economic & Environment & Cycle & DH system \\
\hline$T_{b, \text { prod }}=130^{\circ} \mathrm{C}$ & $p_{\text {el }}=60 \mathrm{EUR} / \mathrm{MWh}$ & $T_{\text {env }}=10.85^{\circ} \mathrm{C}$ & $\eta_{p}=80 \%$ & $T_{\text {supply }}$ \\
$p_{b, \text { prod }}=40 \mathrm{bar}$ & $d_{\text {el }}=1.25 \% /$ year & $p_{\text {env }}=1.02 \mathrm{bar}$ & $\eta_{g}=98 \%$ & $T_{\text {return }}$ \\
$\dot{m}_{b}=150 \mathrm{~kg} / \mathrm{s}$ & $p_{\text {heat }}=25 \mathrm{EUR} / \mathrm{MWh}$ & & $\eta_{m}=98 \%$ & $\dot{Q}_{D H}$ \\
$I_{\text {wells }}=15 \mathrm{MEUR}$ & $d r=5 \%$ & & $\eta_{f}=60 \%$ & $p_{\text {supply }}=7$ bar \\
$\dot{W}_{\text {wells }}=500 \mathrm{~kW}$ & $L=30$ years & & $\Delta T_{\text {min }}=1^{\circ} \mathrm{C}$ & \\
& $N=90 \%$ & & $\Delta T_{\text {sup }}^{\text {min }}=1^{\circ} \mathrm{C}$ &
\end{tabular}

Table 1: Reference parameter values.

by $T_{\text {supply }}$ and $T_{\text {return }}$, is shown in the upper part. The ORC is shown in the lower part. The working fluid is first pumped from a low condenser pressure (state 1) to a higher pressure (state 2). Then, the working fluid is subsequently economized (heated to a saturated liquid), evaporated (to a saturated vapor) and superheated (to state 3 ). The three heat exchangers together are indicated by EES (economizer, evaporator, superheater). Thereafter, the vapor is expanded in the turbine (to state 4), generating work which is converted to electricity by a connected generator. And finally, the vapor is condensed back to the saturated liquid state (state 1), which closes the cycle. This cycle is continuously repeated.

For the heat exchangers, TEMA E shell-and-tube heat exchangers with a $30^{\circ}$ tube layout are considered, with the brine flowing in the tubes [26. An axial turbine is modeled since it is common in geothermal power plants and an air-cooled condenser with flat tubes and corrugated fins is used $27]^{3}$

\subsection{Reference parameter values}

Table 1 shows the reference parameter values. The brine is modeled as pure water and the values related to the brine (production temperature $T_{b, p r o d} \&$ pressure $p_{b, p r o d}$, and mass flow rate $\dot{m}_{b}$ ) and the geothermal wells (investment costs $I_{\text {wells }}$ and well pumps power $\dot{W}_{\text {wells }}$ ) are based on preliminary studies for the Balmatt geological site in Belgium [28].

\footnotetext{
${ }^{3}$ The reader is kindly referred to a previous paper [27] for a more detailed description of the different component types and models.
} 


\footnotetext{
${ }^{4} \eta_{f}=60 \%$ of Table 1 is the total fan efficiency, which includes the isentropic and the mechanical-to-electrical conversion efficiency.

${ }^{5}$ The supply and return temperatures are $T_{\text {supply }}=90^{\circ} \mathrm{C}$ and $T_{\text {supply }}=60^{\circ} \mathrm{C}$, respectively.
} 


\begin{tabular}{c|c|c|c|c|c} 
& $\mathrm{MW}[\mathrm{g} /$ mole $]$ & $T_{\text {crit }}\left[{ }^{\circ} \mathrm{C}\right]$ & $p_{\text {crit }}[\mathrm{MPa}]$ & $\mathrm{ODP}$ & $\mathrm{GWP}$ \\
\hline Isobutane (R600a) & 58.12 & 134.66 & 3.63 & 0 & 20
\end{tabular}

Table 2: Thermodynamic and environmental properties of Isobutane (R600a) 32. ODP and GWP are the abbreviations for the ozone depletion potential and the global warming potential, respectively.

\section{Thermoeconomic design optimization}

The optimal design and the economics of the considered geothermal CHP plant are calculated based on a thermoeconomic optimization model. This model is discussed first, followed by the definition of the performance indicators. Lastly, the optimization results and economic performance indicators are presented for the considered CHP plant.

\subsection{Optimization procedure}

The thermoeconomic design optimization procedure has been described in previous papers [27, 33. and is used in this work. Detailed thermodynamic models for the heat transfer and pressure drop calculations are implemented as well as a correlation for the turbine efficiency. Furthermore, the equipment cost is calculated based on bare equipment cost functions for all components.

The default optimization objective is the net present value (NPV), since it accounts for the thermodynamic performance, the size and cost of the components and the time-dependency of money. The variables to be optimized are the shell-and-tube heat exchangers layout (shell diameter, tube diameter, baffle cut length, tube pitch and the length between the baffles), the air-cooled condenser geometry (height and spacing of the fins and the number of tubes) and the operating conditions (the condenser, evaporator and turbine inlet temperatures, the ORC working fluid flow rate, the air velocity in the condenser and the share of the brine flow rate to the ORC branch). From the optimized variables, many performance indicators, amongst which the generated electrical power output and different cost metrics, can be calculated. In this paper, the focus will be on the cost metrics for application to a low-temperature geothermal CHP plant connected to a DH system. But the philosophy about the cost metrics can be followed for all kinds of CHP plants, and regardless of the energy source. 


\subsection{Definition of the performance indicators}

The NPV is the design optimization objective and is the accounted sum of costs and revenues over the lifetime of the CHP plant. The NPV is defined as:

$N P V=-I_{\text {wells }}-I_{O R C}-I_{D H}+\sum_{i=0}^{L-1} \frac{\left[\dot{W}_{\text {net }} p_{e l}\left(1+d_{e l}\right)^{i}+\dot{Q}_{D H} p_{\text {heat }}\right] 8760 N-0.025\left(I_{O R C}+I_{D H}\right)}{(1+d r)^{i}}$

In the definition of the NPV, $I_{O R C}$ and $I_{D H}$ are the investment costs for the ORC and for the DH system heat exchanger, respectively, and $\dot{W}_{n e t}$ is the net electrical power production. It is understood that although $\dot{W}_{n e t}$ and $\dot{Q}_{D H}$ are power values, they are actually the respective electrical and thermal energy during one timestep, being one hour. The prices are expressed per MWh. Furthermore, the maintenance cost can be estimated as $2.5 \%$ of the equipment investment cost according to the IEA [34. $I_{O R C}, I_{D H}$ and $\dot{W}_{n e t}$ are dependent on the variables of the optimization procedure. For the parameters, the reference values of Table 1 are used. The DH system temperatures and heat demand are (constant) parameters to the optimization procedure. Note that a fixed heat price (assuming a long-term contract) has been assumed, whereas the electricity price increases with $d_{e l}=1.25 \% /$ year. This is based on the European Commission report [35, where they have calculated an average electricity price increase in the EU of $13 \%$ over the period 2010-2020.

The levelized cost of electricity and the levelized cost of heat definitions are found from the NPV definition (Eq. (1)):

- The levelized cost of electricity, for a fixed heat price (which might be zero):

$$
L C O E=\frac{I_{w e l l s}+I_{O R C}+I_{D H}+\sum_{i=0}^{L-1} \frac{\left[0.025\left(I_{O R C}+I_{D H}\right)-\dot{Q}_{D H} p_{\text {heat }} 8760 N\right]}{(1+d r)^{i}}}{\sum_{i=0}^{L-1} \frac{\dot{W}_{n e t}\left(1+d_{e l}\right)^{i} 8760 N}{(1+d r)^{i}}} ;
$$

The LCOE is the price for electricity which is required to break even at the end of the plant's lifetime. Observe that the calculated LCOE value is the required electricity price at the first year of the geothermal plant. A yearly electricity price increase of $d_{e l}=1.25 \%$ is assumed, similar to the NPV calculation in Eq. (1).

- The levelized cost of heat, for a fixed electricity price (which might be zero):

$$
L C O H=\frac{I_{w e l l s}+I_{O R C}+I_{D H}+\sum_{i=0}^{L-1} \frac{0.025\left(I_{O R C}+I_{D H}\right)-\dot{W}_{n e t} p_{e l}\left(1+d_{e l}\right)^{i} 8760 N}{(1+d r)^{i}}}{\sum_{i=0}^{L-1} \frac{\dot{Q}_{D H} 8760 N}{(1+d r)^{i}}} .
$$


The $\mathrm{LCOH}$ is the price for heat which is required to break even at the end of the plant's lifetime.

Furthermore, a new costing mechanism based on the exergy content of heat and electricity is proposed. At this point, it is appropriate to introduce the flow exergy content $\dot{E} x_{D H}$ of the DH system heat demand $\left(\dot{Q}_{D H}\right)$ :

$$
\dot{E x_{D H}}=\dot{m}_{D H}\left(e x_{\text {supply }}-e x_{\text {return }}\right)
$$

with $\dot{m}_{D H}$ the DH system water mass flow rate and the specific exergy $(e x)$ defined as:

$$
e x=h-h_{e n v}-T_{e n v}\left(s-s_{e n v}\right)
$$

wherein the reference conditions are considered equal to the environment conditions (with $T_{e n v}$ and $p_{e n v}$ as given in Table 1 in this work.

Analogous to the $N P V$ which is dependent on the expected energy price, the $N P V_{e x}$ is defined via the price of exergy. The exergy content of thermal energy and the electrical energy are priced with the same price for exergy $p_{e x}$. Similar to the LCOE and LCOH, the levelized cost of exergy (LCOEx) is defined. It is the price for (thermal or electrical) exergy which is required to break even at the end of the plant's lifetime 6 . The definitions for $N P V_{e x}$ and LCOEx are:

- The NPV, based on exergy:

$$
\begin{aligned}
& N P V_{e x}=-I_{\text {wells }}-I_{O R C}-I_{D H} \\
& \quad+\sum_{i=0}^{L-1} \frac{\left[\left(\dot{W}_{n e t}+\dot{E x_{D H}}\right) p_{e x}\left(1+d_{e l}\right)^{i}\right] 8760 N-0.025\left(I_{O R C}+I_{D H}\right)}{(1+d r)^{i}}
\end{aligned}
$$

- The levelized cost of exergy:

$$
L C O E x=\frac{I_{w e l l s}+I_{O R C}+I_{D H}+\sum_{i=0}^{L-1} \frac{0.025\left(I_{O R C}+I_{D H}\right)}{(1+d r)^{i}}}{\sum_{i=0}^{L-1} \frac{\left(\dot{W}_{n e t}+E x_{D H}\right)\left(1+d_{e l}\right)^{i} 8760 N}{(1+d r)^{i}}} .
$$

Since the quality factor for electricity equals unity, the energy content and the exergy content are equal $\left(\dot{W}_{n e t}=\dot{E} x_{e l}\right)$. This explains why $\dot{W}_{n e t}$ is used in Eqs. (6) and (7). For heat, the quality factor is less than one, and the thermal exergy flow content $E x_{D H}$ is used.

\footnotetext{
${ }^{6}$ As for the LCOE, the LCOEx from Eq. $\sqrt{7}$ is the required exergy price at the first year of the geothermal plant and a yearly exergy price increase of $1.25 \%$ is assumed.
} 
3.3. Results

The results are shown for a low-temperature geothermal CHP plant, connected to a 90/60 and a $65 / 40 \mathrm{DH}$ system, and for three values of the heat demand. The investigation of different types of DH systems is interesting because of the temperature-dependency of exergy. Multiple values for the heat demand are considered since a higher heat demand means a lower electrical power generation, and the effect on the project economic feasibility can be studied.

\subsubsection{Results for two different district heating systems and for multiple heat demands}

Table 3 shows the most important performance indicators for the design optimization of the geothermal CHP plant from Fig. 1, and for the reference parameters of Table11. For reasons of comparison, the results for the stand-alone electrical power plant (indicated by $O R C$ ) for the same parameter values are shown in the first column. Then, the results for a CHP plant connected to a $65 / 40 \mathrm{DH}$ system are shown, followed by the results for a CHP plant connected to a 90/60 DH system (which all have a different optimized design). For now, only consider the values above the double bars. The additional performance indicators listed underneath the double bars will be discussed in Section 4.2 .

The NPV is the objective of the design optimization procedure. From the results, it follows that the economic attractiveness can be increased by producing heat next to electricity for the investigated parameter values, since for all cases the NPV of the CHP plants is higher than for the stand-alone electrical power plant. However, the electrical power output $\dot{W}_{n e t}$ decreases with the heat demand and with the temperatures of the DH system. This is a direct consequence of the higher brine flow rate which is needed to satisfy higher heat demands or to satisfy the same heat demand at higher temperatures. As for the net electrical power output $\dot{W}_{n e t}$, the NPV is lower for the connection to a higher-temperature DH system (due to the lower $\dot{W}_{n e t}$ ). However, the NPV increases with the heat demand as a result of the higher incomes from selling heat.

Also the NPV based on exergy content, as defined in Eq. (6), has been calculated. In this calculation, the exergy price $p_{e x}$ is assumed equal to the reference electricity price $p_{e l}$ of Table 1 $N P V_{e x}$ is lower than $N P V$ because the incomes from selling heat are lower in the $N P V_{e x}$ calculation $\left(\sim \dot{E} x_{D H} p_{e x}\left(1+d_{e l}\right)^{i}\right)$ than in the NPV calculation $\left(\sim \dot{Q}_{D H} p_{\text {heat }}\right)$. As for the $N P V$, $N P V_{e x}$ increases with the heat demand due to the higher incomes from selling heat. However, in 


\begin{tabular}{|c|c|c|c|c|c|c|c|}
\hline & ORC & \multicolumn{3}{|c|}{$65 / 40 \mathrm{DH}$ system } & \multicolumn{3}{|c|}{ 90/60 DH system } \\
\hline$\dot{Q}_{D H}[\mathrm{MWth}]$ & 0 & 5 & 10 & 20 & 5 & 10 & 20 \\
\hline$\dot{E x_{D H}}[\mathrm{MWth}]$ & 0 & 0.64 & 1.27 & 2.55 & 0.92 & 1.84 & 3.67 \\
\hline$\dot{W}_{\text {net }}[\mathrm{MWe}]$ & 3.11 & 2.77 & 2.43 & 1.77 & 2.67 & 2.24 & 1.37 \\
\hline$N P V[\mathrm{MEUR}]$ & -3.74 & 10.33 & 24.53 & 53.00 & 9.82 & 23.52 & 51.06 \\
\hline$N P V_{e x}[\mathrm{MEUR}]$ & -3.74 & 0.02 & 3.91 & 11.76 & 1.98 & 7.85 & 19.72 \\
\hline$L C O E, p_{\text {heat }}=0[\mathrm{EUR} / \mathrm{MWhe}]$ & 68.20 & 73.73 & 80.43 & 100.98 & 75.55 & $\begin{array}{ll}85.27 \\
8\end{array}$ & 122.71 \\
\hline$L C O H, p_{e l}=0[\mathrm{EUR} / \mathrm{MWhth}]$ & - & 47.06 & 22.54 & 10.30 & 46.53 & $\begin{array}{l}22.00 \\
2\end{array}$ & 9.67 \\
\hline LCOEx [EUR/MWhex] & 68.20 & 59.96 & 52.80 & 41.42 & 56.24 & $\begin{array}{l}46.85 \\
4\end{array}$ & 33.31 \\
\hline$L C O E[\mathrm{EUR} / \mathrm{MWhe}]$ & 68.20 & 34.57 & -8.76 & -144.06 & 34.96 & -11.65 & -194.32 \\
\hline $\mathrm{LCOH}[\mathrm{EUR} / \mathrm{MWhth}]$ & - & 8.77 & 5.73 & 4.18 & 9.58 & 6.52 & 4.94 \\
\hline LCOEn [EUR/MWhen] & 68.20 & 28.73 & 17.61 & 9.36 & 28.80 & $\begin{array}{l}17.48 \\
1\end{array}$ & 8.96 \\
\hline$S I C_{e n}[\mathrm{EUR} / \mathrm{kWen}]$ & 8510 & 3301 & 1991 & 1056 & 3311 & $\begin{array}{ll}1982 \\
1\end{array}$ & 1022 \\
\hline$S I C_{e l}[\mathrm{EUR} / \mathrm{kWel}]$ & 8510 & 9258 & 10174 & 12976 & 9503 & 10832 & 15954 \\
\hline$S I C_{t h}[\mathrm{EUR} / \mathrm{kWth}]$ & - & 5130 & 2475 & 1149 & 5082 & 2426 & 1092 \\
\hline$S I C_{e x}[\mathrm{EUR} / \mathrm{kWex}]$ & 8510 & 7529 & 6679 & 5324 & 7074 & 5952 & 4334 \\
\hline
\end{tabular}

Table 3: Performance indicators (calculated based on the results of the design optimization procedure) for the parallel geothermal CHP plant, for the connection to a 65/40 and a 90/60 DH system and for three different heat demands. The results for the stand-alone electrical power plant (ORC) are given for comparison. To recall, the assumed price for electricity in Table 1 was equal to $p_{e l}=60 E U R / M W h$, while the price for heat was $p_{\text {heat }}=25 E U R / M W h$ (relevant for the NPV computation and to be compared with the levelized costs). LCOE and $L C O H$ account for the reference price for heat and electricity, respectively, whereas for $L C O E, p_{\text {heat }}=0$ the heat price is zero and for $L C O H, p_{e l}=0$ the electricity price is zero. 
contrast to the $N P V$ and $\dot{W}_{n e t}, N P V_{e x}$ is higher for the connection to a higher-temperature DH system due to the higher exergy content of heat, so higher incomes from selling heat exergy are generated.

Fig. 2 shows the LCOE as a function of the heat price. The lines for the LCOE (so, the electricity price for which $N P V=0$ ) of the CHP plant are given by the negatively-sloped straight lines. All points above the given negatively-sloped lines are economically feasible, with a combination of $p_{e l}$ and $p_{\text {heat }}$ for which the CHP plant is profitable (with $N P V>0$ ). The black full horizontal line gives the LCOE for the stand-alone electrical power plant. The results for the connection to a 65/40 DH system are shown in blue, for three values of the heat demand: 5MWth (dotted line), 10MWth (dash-dotted line) and 20MWth (dashed line). The intersection point of the blue lines with the black line indicates the heat price for which the LCOE for the CHP plant equals the LCOE of the stand-alone electrical power plant. For heat prices above this value, the CHP plant is economically more attractive than the stand-alone electrical power plant. Note that the heat prices for which the CHP plant becomes more attractive are very low: $p_{\text {heat }}=2.39,2.92$ and $3.16 \mathrm{EUR} / \mathrm{MWh}$ for heat demands of 5, 10 and 20MWth, respectively. So, in almost all cases, a CHP plant is economically more attractive than a stand-alone power plant for the investigated low values of the electricity price (which are common values for Belgium).

The green negatively-sloped straight lines indicate the LCOE for the connection to a 90/60 DH system. In comparison to the $65 / 40 \mathrm{DH}$ system (blue lines), heat at higher temperatures is required. From Table 3 , it follows that the electrical power production is lower. As a result, for the same heat demand, higher electricity prices are needed for low values of $p_{\text {heat }}$. For higher values of $p_{\text {heat }}$, the electricity prices are almost the same as for the $65 / 40 \mathrm{DH}$ system. Actually, for high values of $p_{\text {heat }}$, slightly lower electricity prices are needed for the connection to a 90/60 DH system than for a $65 / 40 \mathrm{DH}$ system. For the connection to a $90 / 60 \mathrm{DH}$ system, the electrical power output is lower but also the investments in the ORC $\left(I_{O R C}\right)$ are lower which explains this trend. Furthermore, the intersection point with the stand-alone electrical power plant line is at slightly higher values for $p_{\text {heat }}$ compared to the $65 / 40 \mathrm{DH}$ system connection. The values of the intersection points are at $p_{\text {heat }}=3.41,3.94$ and 4.15EUR/MWh for heat demands of 5, 10 and 20MWth, respectively.

The intersection with the ordinate axis gives the LCOE for $p_{\text {heat }}=0$. These values are also given in Table 3. $L C O E, p_{\text {heat }}=0$ increases for a higher heat demand and for higher temperature levels 


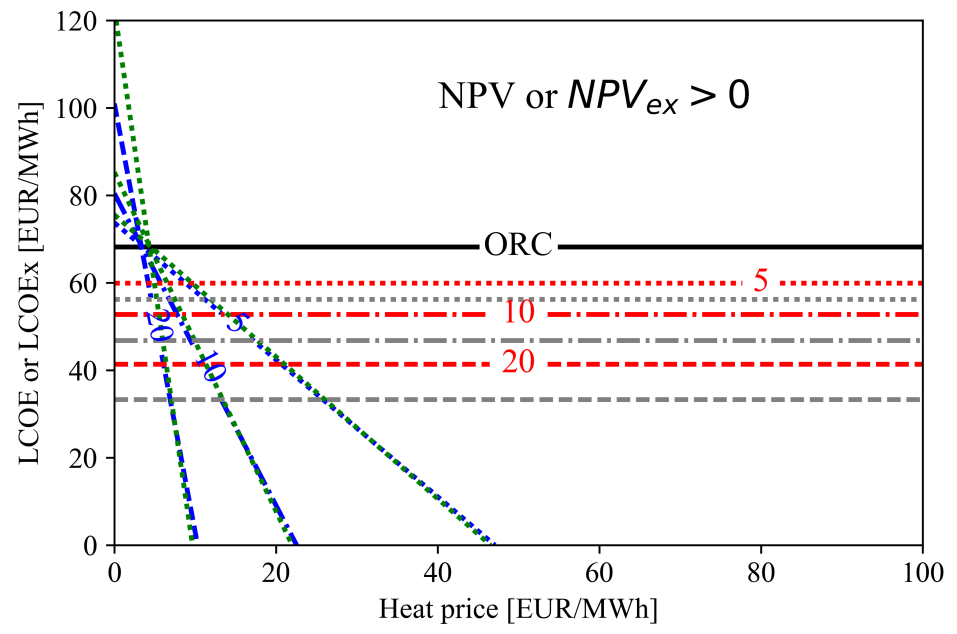

Figure 2: Levelized cost of electricity (LCOE) as a function of the heat price, for the stand-alone electrical power plant (black), for the CHP plant connected to a 65/40 DH system (blue) and for the 90/60 DH system connection (green). The dotted, dash-dotted and dashed lines indicate a heat demand of 5, 10 and 20MWth, respectively. The red horizontal lines present the levelized cost of exergy (LCOEx) for the CHP plant connected to a 65/40 DH system. In gray, the lines for the $90 / 60 \mathrm{DH}$ system are shown. $L C O E=L C O E x$ for a stand-alone electrical power plant (full black line). 
of the heat demand, which is logical. Similarly, the $\mathrm{LCOH}$ for $p_{e l}=0$ is given on the abscissa axis. As expected, $L C O H, p_{e l}=0$ is higher for a lower heat demand. $L C O H, p_{e l}=0$ is higher for lower temperatures of the DH system because the electrical power output is higher, and the investments in the ORC have to be covered by the revenues from selling heat. Also these values are shown in Table 3

Finally, the new economic metric - the levelized cost of exergy (LCOEx) - is also shown in Fig. 2 for the stand-alone electrical power plant (in black) and for the CHP plants with different heat demands (in red for the 65/40 DH system connection and in gray for the connection to a 90/60 DH system). Note that the lines for the LCOEx do not depend on the heat price, since the same price is assumed for one MWh of electricity as for one MWh of thermal exergy. The LCOEx is defined as the price per MWh of (thermal or electrical) exergy which is required over the lifetime of the project, to break even at the end of its lifetime. This metric is based on the exergy concept, and makes no distinction between exergy from electrical and thermal energy. For the stand-alone electrical power plant, $L C O E x=L C O E$. For the CHP plants, exergy is delivered by thermal or electrical energy and the LCOEx decreases with the heat demand, as can also be seen in Table 3 . A higher heat demand means that the total exergy production is higher, so a lower price is sufficient to break even at the end of the CHP plant's lifetime. Furthermore, the LCOEx values are lower for a higher-temperature DH system due to the higher exergy content of the same amount of thermal energy.

\subsubsection{Note on the temperature-dependency of exergy}

From Table 3, it was already clear that the exergy content of the same amount of heat asked by a 90/60 DH system is higher than for a 65/40 DH system. This is further explained using Fig. 3

The specific exergy is a state property which is defined with respect to a reference state. For this reference state, the average ambient conditions for Belgium in 2016 are considered. The specific exergy is the amount of work that one $\mathrm{kg}$ of fluid (at a certain temperature $T$ and pressure $p$ ) could maximally deliver with respect to the environment at $T_{e n v}$ and $p_{e n v}$ (values of Table 1). From Fig. 3 it follows that $e x$ increases exponentially with the temperature. This explains why the specific thermal exergy of the $90 / 60 \mathrm{DH}$ system $(e x=23.11 \mathrm{~kJ} / \mathrm{kg})$ is higher than that of the 


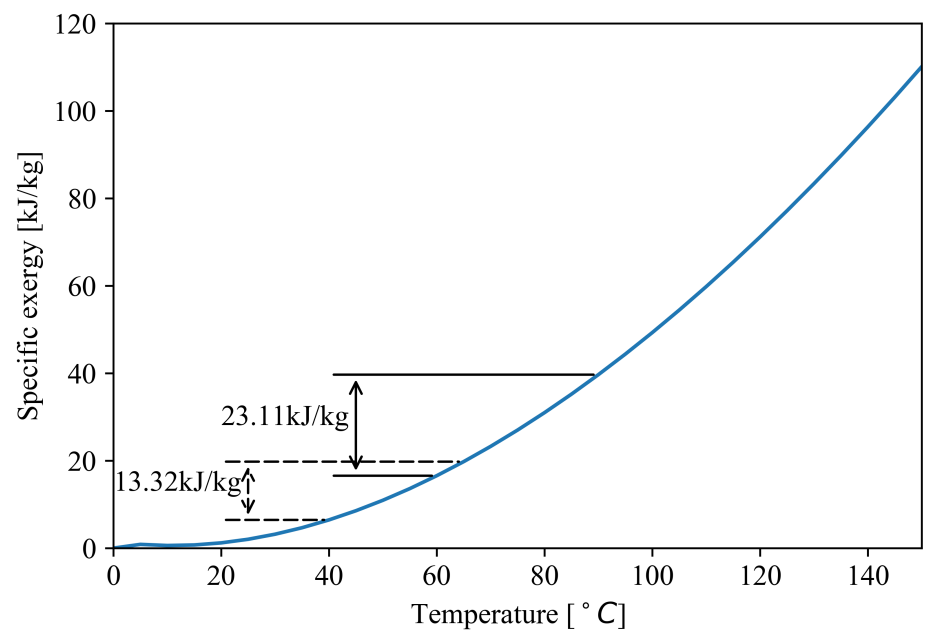

Figure 3: Specific exergy as a function of temperature, for water at $p_{D H}=7 \mathrm{bar}$ and with respect to the average ambient conditions (as given in Table 1).

lower-temperature $65 / 40 \mathrm{DH}$ system $(e x=13.32 \mathrm{~kJ} / \mathrm{kg})$. This is also the reason why the LCOEx for the CHP plant connected to a 90/60 DH system (gray lines in Fig. 22) is lower than for the CHP plant connected to a $65 / 40 \mathrm{DH}$ system.

\subsubsection{Note on the optimization objective}

The result of the optimization procedure is the optimal CHP plant design which corresponds to the highest NPV. However, one could wonder why the $N P V_{e x}$ has not been considered as the optimization objective. If the $N P V_{e x}$ would have been the optimization objective, the results (optimal CHP plant design and performance indicators, e.g., $\dot{W}_{n e t}$ ) would be the same. This is because (the optimal values of) the variables do not depend on the electricity or heat prices, since they are (fixed) parameters to the optimization procedure.

\section{Discussion}

In this section, the metrics for the economic characterization of a CHP plant will be extended, with each metric having its own viewpoint to the same CHP plant. Furthermore, different costing 
methods will be defined and applied to two economic scenarios. Finally, some general guidelines will be presented.

\subsection{Definition of some more performance indicators}

Some additional performance indicators are defined:

- The levelized cost of energy:

$$
L C O E n=\frac{I_{w e l l s}+I_{O R C}+I_{D H}+\sum_{i=0}^{L-1} \frac{0.025\left(I_{O R C}+I_{D H}\right)}{(1+d r)^{i}}}{\sum_{i=0}^{L-1} \frac{\left(\dot{W}_{n e t}\left(1+d_{e l}\right)^{i}+\dot{Q}_{D H}\right) 8760 N}{(1+d r)^{i}}} ;
$$

The LCOEn is the price for (thermal or electrical) energy which is required to break even at the end of the plant's lifetime.

- The specific investment cost, based on total energetic power:

$$
S I C_{e n}=\frac{I_{w e l l s}+I_{O R C}+I_{D H}}{\dot{W}_{n e t}+\dot{Q}_{D H}} ;
$$

- The specific investment cost, based on electrical power:

$$
S I C_{e l}=\frac{I_{w e l l s}+I_{O R C}+I_{D H}}{\dot{W}_{n e t}} ;
$$

- The specific investment cost, based on heat (thermal power):

$$
S I C_{t h}=\frac{I_{w e l l s}+I_{O R C}+I_{D H}}{\dot{Q}_{D H}} ;
$$

- The specific investment cost, based on total exergetic power:

$$
S I C_{e x}=\frac{I_{w e l l s}+I_{O R C}+I_{D H}}{\dot{W}_{n e t}+\dot{E x_{D H}}} .
$$

The specific investment cost gives the investment costs per $\mathrm{kW}$ of representative energy or exergy which is produced. The representative energy/exergy form depends on the application.

\subsection{Costing methods}

From the levelized cost concepts, the LCOE is the most well-known concept. Similarly, the SIC based on electricity is the most well-known. Both of them are mature concepts for electrical power 
plants. However, when dealing with heat and electricity, the energy producer can choose how to allocate costs. If all costs are allocated to the electricity production, the LCOE and $S I C_{e n}$ can still be used. Alternatively, the costs can also be allocated to the heat production alone (LCOH, SIC $t h$ ) or to electricity and heat production together (LCOEn, $S I C_{e n}$ ). However, the exergy concept (with the LCOEx) is more appropriate ${ }^{7}$ for a CHP plant, since there is no distinction between electricity and heat. Furthermore, the amount of energy and the usefulness of heat at different temperatures are taken into account.

The different costing methods are 8

1. Electricity costing method, either allocating all costs to the electricity production $\left(p_{\text {heat }}=0\right)$ or for a fixed heat price $\left(p_{\text {heat }} \neq 0\right)$;

2. Heat costing method, either allocating all costs to the heat production $\left(p_{e l}=0\right)$ or for a fixed electricity price $\left(p_{e l} \neq 0\right)$;

3. Energy costing method, using the same price for heat and electricity;

4. Exergy costing method, using the same price for the exergy content of heat and electricity.

The additional performance indicators are added to Table 3, below the double bars. Based on Table 3. all levelized cost concepts will be discussed for application to a geothermal CHP plant.

For the $L C O E, p_{\text {heat }}=0$, all costs are allocated to the electricity production. In comparison to the stand-alone electrical power plant, the LCOE is higher due to the higher investment costs and the LCOE is higher for the connection to a higher-temperature DH system, which is expected.

For the $L C O H, p_{e l}=0$, all costs are allocated to the heat production. The $\mathrm{LCOH}$ does not exist for a stand-alone electrical power plant. As is logical, the LCOH decreases with the heat demand,

\footnotetext{
${ }^{7}$ With the term appropriate, the authors mean that the respective cost metric is the most suited for the investigated case. The LCOEx is the appropriate levelized cost metric for CHP plants, since it accounts for the two products and for the usefulness of every product. So it makes more sense to use the LCOEx instead of the LCOE, the LCOH or the LCOEn for this purpose.

${ }^{8}$ Note that the terms energy and power are used indiscriminately throughout the paper. Over the assumed timestep of one hour, $1 \mathrm{MWh}$ of thermal or electrical energy is the result of a thermal or electrical power output of $1 \mathrm{MW}$ over a period of one hour. Prices are expressed in EUR/MWh, so the corresponding energy unit should be used for cost calculations.
} 
and is higher for the $65 / 40 \mathrm{DH}$ system connection due to the higher electrical power production (so higher ORC investment costs).

The LCOE is the levelized cost of electricity, assuming a fixed heat price of $p_{\text {heat }}$ for selling heat. Similarly the $\mathrm{LCOH}$ is the levelized cost of heat, assuming a reference electricity price of $p_{e l}$ for selling electricity. The LCOE and LCOH decrease with the heat demand, since the incomes from selling heat are higher. The LCOE can become negative, at sufficiently high heat prices, when no additional incomes from selling electricity are required to have $N P V \geq 0$. Note that the LCOE decreases faster with the heat demand for the 90/60 DH system due to the lower electrical power production $\dot{W}_{n e t}$. The LCOH is higher for the $90 / 60 \mathrm{DH}$ system due to the lower revenues from selling electricity (because of the lower value of $\dot{W}_{n e t}$ ).

The levelized cost of energy (LCOEn) considers the same price for both, thermal and electrical energy which, in this case, is taken as the weighted average of $p_{e l}$ and $p_{h e a t}$. As can be expected, LCOEn is lower for higher heat demands since more energy is produced by the CHP. For low heat demands, the investment costs are high compared to the energy production and the LCOEn is higher for the 90/60 DH system. However for higher heat demands, the electricity production for the 90/60 DH system case is lower (so are the ORC investment costs) and the LCOEn for the 90/60 DH system connection is lower than for the 65/40 DH system connection (where the ORC investments are still significant).

Finally, the LCOEx concept considers thermal and electrical energy but also accounts for the temperature levels of the thermal energy. The philosophy behind this concept is that heat at higher temperatures, which is more useful, should have a higher price than heat at lower temperatures. The LCOEx decreases with the heat demand and decreases faster when heat at higher temperatures (and thus a higher exergy content) is required.

The $S I C_{e n}, S I C_{e l}, S I C_{t h}$ and $S I C_{e x}$ follow the same trends as the LCOEn, LCOE, $p_{\text {heat }}=0$, $L C O H, p_{e l}=0$ and $L C O E x$, respectively, and are also shown in Table 3.

\subsection{Application to two different economic scenarios}

The different costing methods will now be discussed for two economic scenarios. The first scenario $(R E F)$ is for the reference values of $p_{e l}=60 E U R / M W h$ and $p_{\text {heat }}=25 E U R / M W h$ from Table 
1. This scenario is suggested by the economic conditions for the wholesale prices in Belgium (without some kind of support scheme) [29. For the second scenario, $p_{e l}=250 E U R / M W h$ and $p_{\text {heat }}=50 E U R / M W h$ are considered. This scenario is inspired by the retail prices in Germany, including feed-in tariffs (a kind of support scheme, and is indicated by $S U P$ ) [36. For all cases, a price of exergy equal to the electricity price $p_{e x}=p_{e l}$ is assumed and an energy price $p_{e n}=$ $x p_{e l}+(1-x) p_{\text {heat }}$, with the fraction $x$ being the ratio of the electrical energy to the total energy produced by the CHP.

Fig. 4 shows the actual annualized hourly revenues for every costing method. The hourly revenues are calculated based on the actual prices for heat and electricity in each scenario, which are different from the required prices to break even (so for which $N P V=0$ ). Positive revenues indicate a profitable project $(N P V>0)$ whereas negative values indicate an unfeasible project $(N P V<0)$. Note that the CHP plant has been designed for the parameter values of Table 1 .

The color bars represent the revenues for each costing method for the CHP plant connected to a $65 / 40 \mathrm{DH}$ system and for different values of the heat demand. The first gray bar indicates the stand-alone electrical power plant for comparison. The black bars without fill represent the results for the CHP plant connected to a 90/60 DH system. The dashed and full lines show the maximal revenues for the actual electricity and heat prices for the $65 / 40 \mathrm{DH}$ system and the $90 / 60 \mathrm{DH}$ system connection, respectively.

First, consider Fig. 4a, which gives the results for typical Belgian wholesale conditions. The first bar once again shows that the stand-alone electrical power plant is not economically feasible for the conditions of Table 1 (revenues $<0$ ). The other bars indicate the revenues of the CHP plant based on the actual occurring prices $\left(p_{e l}=60 E U R / M W h\right.$ and $\left.p_{\text {heat }}=25 E U R / M W h\right)$ of blindly applying the costing methods. Since the actual prices differ from the required value of the respective levelized cost indicator, the revenues are different from zero. For the different costing methods applied to the CHP plant holds:

- The blind application of the electricity costing method with $p_{\text {heat }}=0$ (blue) results in an economically unfeasible project. Only revenues from selling electricity are generated. However, the actual price is lower than the price which is required by the cost metric: $p_{e l}<L C O E, p_{\text {heat }}=0$; 


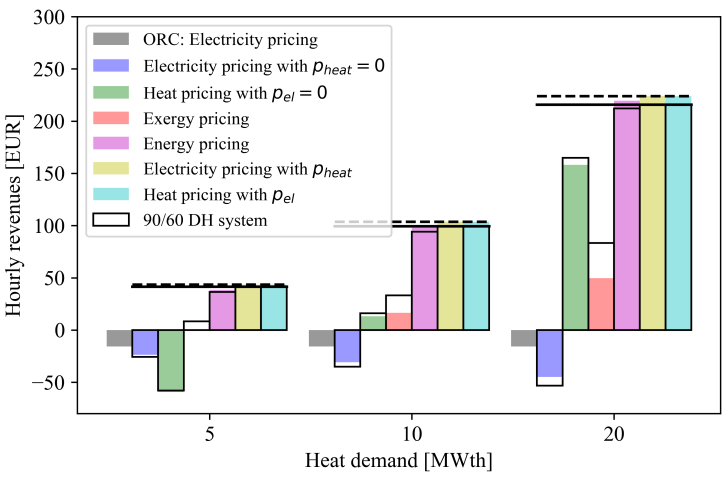

(a) REF: $p_{\text {el }}=60 \& p_{\text {heat }}=25 E U R / M W h[29$.

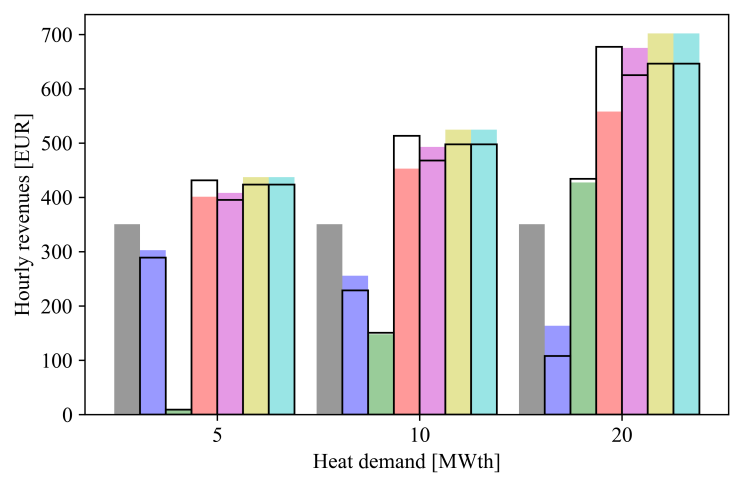

(b) SUP: $p_{e l}=250 \& p_{\text {heat }}=50 E U R / M W h$ [36].

Figure 4: Real hourly revenues of blindly applying the different costing methods to customers, for two different scenarios for the electricity and heat prices. Left: scenario with low electricity and heat prices $(R E F)$. Right: scenario with high prices for electricity and heat $(S U P)$.

- Also, the application of the heat costing method with $p_{e l}=0$ (green) results in an unfeasible project for a low heat demand of $\dot{Q}_{D H}=5 M W t h$. However, for the heat demands of 10 and 20MWth, the project is economically feasible;

- The exergy costing method (red) always results in a profitable project. The revenues are higher for higher heat demands and for higher temperatures of the required heat (due to the higher amount of exergy);

- The energy costing method with the weighted average price for thermal and electrical energy (purple) is also always attractive, and results in higher revenues for higher heat demands and lower temperatures of the required heat. The revenues are slightly lower than the maximal revenues 9 , which are indicated by the dashed lines for the $65 / 40 \mathrm{DH}$ system and by the full lines for the $90 / 60 \mathrm{DH}$ system;

- The electricity costing method for a fixed heat price $p_{\text {heat }}=25 E U R / M W h$ (yellow) and the heat costing method for a fixed electricity price $p_{e l}=60 E U R / M W h$ (cyan) correspond to the maximal revenues which are possible, given the actual heat and electricity prices.

\footnotetext{
${ }^{9}$ The energy costing method is actually the same, however, without accounting for the electricity price increase over the years but just taking the weighted average of the prices for heat and electricity.
} 
Note that for the considered actual electricity, heat and exergy prices, none of the costing methods can blindly be applied. For all of the methods, the revenues are lower than the potential maximal revenues, which are the result of the conventional costing mechanism (sell electrical and thermal energy at $p_{e l}$ and $p_{\text {heat }}$, respectively). However, the application of all costing methods, except the electricity costing method with $p_{\text {heat }}=0$ (blue) and the heat costing method with $p_{e l}=0$ (green) at low heat demands, still result in an economically attractive CHP plant $(N P V>0)$. The energy costing method with the weighted average price for thermal and electrical energy method is closest to the revenues from the conventional costing method, which nearly equals the costing methods of the last two bars.

Fig. $4 \mathrm{~b}$ shows the results for higher electricity and heat prices, which are typical for the situation with support scheme. The first bar shows the revenues for the stand-alone electrical power plant given the actual electricity price. For this high electricity price ${ }^{10}$, the stand-alone electrical power plant is economically feasible. However, the revenues and the economic feasibility of the geothermal project can still be improved by providing heat next to electricity. In this case, the application of all costing methods to the CHP plant results in a profitable project (however not all methods are equally in demand). The trends are similar to Fig. 4a but note the different ordinate scale. The last two bars, for the electricity costing method for a fixed heat price $p_{\text {heat }}=50 E U R / M W h$ (yellow) and the heat costing method for a fixed electricity price $p_{e l}=250 E U R / M W h$ (cyan), reflect the conventional costing method. This is the best costing method for the connection to a lowtemperature DH system. However, for the connection to a higher-temperature 90/60 DH system, the LCOEx concept results in the highest revenues. This is mainly due to the high electricity price compared to the heat price and the $p_{e x}=p_{e l}$ consideration, and due to the higher exergy content of higher-temperature heat. Also due to the larger relative significance of $p_{e l}$ compared to $p_{\text {heat }}{ }^{11}$ the electricity costing method with $p_{\text {heat }}=0$ (blue) has relatively better performance compared to the heat costing method with $p_{e l}=0$ (green), especially at low heat demands.

Whether or not the costing method results in an economically feasible project (with $N P V>0$ ), depends on the actual prices for electricity and heat.

${ }^{10}$ Note the very high electricity price (thanks to the feed-in tariffs) compared to the case without feed-in tariffs in Fig. $4 \mathrm{a}$

${ }^{11}$ Note that the electricity-to-heat price ratio is $2.4: 1$ for Fig. $4 \mathrm{a}$ whereas it is $5: 1$ for Fig. $4 \mathrm{~b}$ 


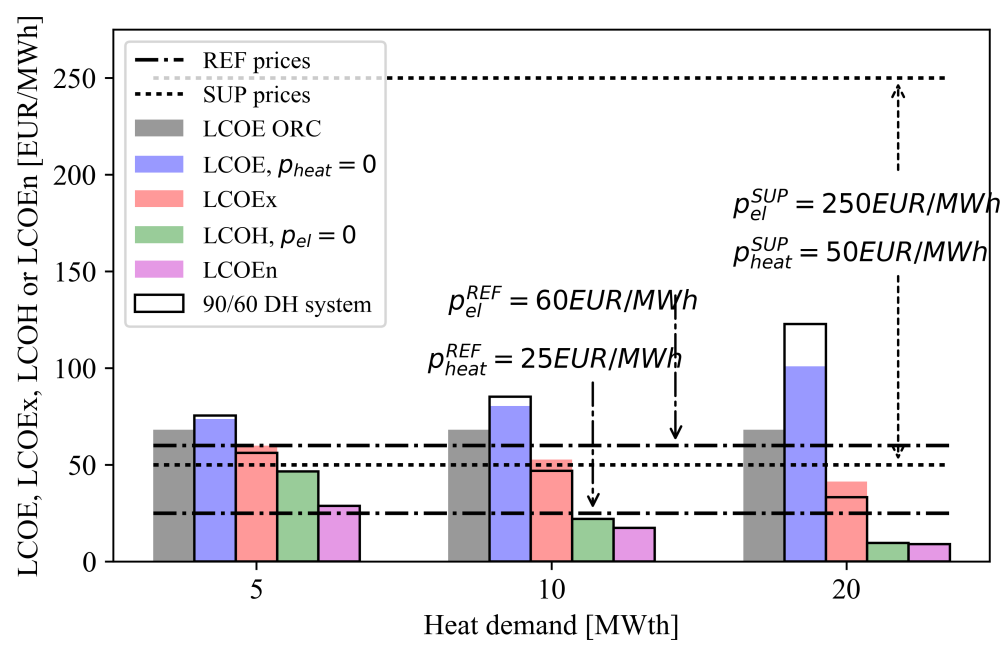

Figure 5: LCOE, $p_{\text {heat }}=0, L C O H, p_{e l}=0, L C O E n$ and LCOEx of the parallel geothermal CHP plant for the connection to a $65 / 40 \mathrm{DH}$ system (colored bars) and for the connection to a 90/60 DH system (black bars without fill). For comparison reasons, the LCOE of a stand-alone electrical power plant is given by the gray bar. The dash-dotted and the dotted lines give the actual prices for electricity and heat for the reference case (based on the Belgian wholesale scenario with values from Table 1 indicated by $R E F$ ) and for the scenario with support scheme (indicated by $S U P$ ), respectively.

\subsection{General guidelines}

Fig. 5 shows the different levelized cost metrics for the geothermal CHP plant, for the connection to a 65/40 DH system (colored bars) and a 90/60 DH system (black boxes without fill) and for three values of the heat demand.

In general, the costing methods are profitable $(N P V>0)$ in the following cases:

- Electricity costing method with $p_{\text {heat }}=0$ for $L C O E<p_{e l}$;

- Heat costing method with $p_{e l}=0$ for $L C O H<p_{\text {heat }}$;

- Energy costing method for $L C O E n<x p_{e l}+(1-x) p_{\text {heat }}$, with $x$ the share of electricity in the total produced (thermal and electrical) energy;

- Exergy costing for $L C O E x<p_{e x}$. In this paper, the price for exergy $p_{e x}$ is chosen equal to the electricity price $p_{e l}$, but this price may be different. 
For illustration, the actual prices for heat and electricity which are considered in this study, are also given in Fig. 5. The dash-dotted lines present the reference prices (indicated by $R E F$ ) and the dotted lines indicate the prices for the scenario with support scheme (indicated by $S U P$ ).

The energy producer does not want to allocate all costs to electricity and sell heat for free. This leads to a higher LCOE than for a stand-alone electrical power plant. Even more, the electricity price in the reference case is lower than $L C O E$, $p_{\text {heat }}=0$, so this results in a negative economic balance. Also the opposite is true. The producer generally does not want to sell the electricity for free (since the ORC part needs the biggest investments) and generate incomes from selling heat only. For the REF case, $L C O H, p_{e l}=0>p_{\text {heat }}^{R E F}$ and this costing method does not result in an economically attractive project, however for the $S U P$ case, the heat costing method with $p_{e l}=0$ results in an economically feasible project since $L C O H, p_{e l}=0<p_{\text {heat }}^{S U P}$. It would be a lot more beneficial, however, to invest in a heat exchanger for heat generation only. The LCOH would range from 6.18EUR/MWh for a $65 / 40 \mathrm{DH}$ system and $\dot{Q}_{D H}=20 \mathrm{MWth}$ to $24.08 \mathrm{EUR} / \mathrm{MWh}$ for a $90 / 60 \mathrm{DH}$ system and $\dot{Q}_{D H}=5 \mathrm{MWth}$. By doing so, the $\mathrm{LCOH}$ would be lower than the heat price in both cases. Furthermore, the producer would like to use the energy costing method. Since the electricity and heat prices are generally higher than the required LCOEn-value, this price allocation method results in an economically attractive project. And finally, the exergy costing method is also attractive, and even more for high heat demands and for a heat demand at high temperatures. Since the heat is appropriately valued based on its temperature level, this costing method is closest related to thermoeconomics.

\section{Conclusions}

In this paper, the design optimization of a geothermal combined heat-and-power (CHP) plant towards maximal net present value (NPV) has been investigated. This NPV calculation is based on parameter assumptions for the electricity and heat prices. However, once the CHP plant is installed, the price allocation to heat and electricity can be done according to certain costing methods. Therefore, different levelized cost metrics and specific investment cost definitions have been defined. Also different costing methods have been discussed and applied to a CHP plant fueled by low-temperature geothermal energy, which is a (near) zero-marginal cost energy source. 
A general rule states that the application of a certain costing method to the customers results in an economically profitable project $(N P V>0)$ if the actual price is higher than the corresponding levelized cost metric. The results are given for the reference scenario $(R E F)$ with actual prices for heat and electricity of 25 and 60EUR/MWh, respectively, and for a scenario with high feed-in tariffs $(S U P)$ and corresponding heat and electricity prices of 50 and 250EUR/MWh. For the REF scenario, the application of the conventional costing mechanism (with fixed prices for heat and electricity) results in the highest revenues. However for the SUP scenario, the conventional costing mechanism is the most convenient for the connection to a low-temperature $65 / 40$ DH system, whereas the exergy costing method results in higher revenues for the connection to a higher-temperature 90/60 DH system. The exergy price is assumed equal to the electricity price in this work, but this value might be different. In general, the exergy costing method results in higher revenues in case of higher heat demands, higher temperatures of the heat demand and a larger difference between the exergy price and the heat price.

The authors recommend the use of the novel levelized cost of exergy (LCOEx) metric since it is closest related to thermoeconomics and different types of energy products can be represented with a single value. Depending on the amount of energy and the usefulness of the energy type (e.g., for heat depending on the temperature level), an appropriate cost can be allocated to each product of a multi-energy system.

\section{Acknowledgments}

This project receives the support of the VITO PhD grant number 1510829. The first author would like to thank dr. Ben Laenen and the VITO management for making this project possible. 
Nomenclature

548

Abbreviations

549

\begin{tabular}{cc}
\hline symbol & description \\
\hline CHP & combined heat-and-power \\
DH & district heating \\
EGS & engineered geothermal system \\
EES & economizer, evaporator, superheater \\
GWP & global warming potential \\
LNG & liquefied natural gas \\
ODP & ozone depletion potential \\
O\&M & operation and maintenance \\
ORC & organic Rankine cycle \\
PV & photovoltaic \\
REF & reference scenario \\
SUP & scenario with support scheme \\
\hline
\end{tabular}




\begin{tabular}{|c|c|}
\hline symbol & description \\
\hline$d_{e l}[\% /$ year $]$ & electricity price increase \\
\hline$d r[\%]$ & discount rate \\
\hline$\dot{E}[\mathrm{MWth}]$ & flow exergy \\
\hline$e x[\mathrm{~kJ} / \mathrm{kg}]$ & specific flow exergy \\
\hline$h[\mathrm{~kJ} / \mathrm{kg}]$ & specific enthalpy \\
\hline$I[\mathrm{MEUR}]$ & investment cost \\
\hline $\operatorname{IRR}[\%]$ & internal rate of return \\
\hline$L$ [year] & lifetime \\
\hline$L C O E[\mathrm{EUR} / \mathrm{MWh}]$ & levelized cost of electricity \\
\hline LCOEn $[\mathrm{EUR} / \mathrm{MWh}]$ & levelized cost of energy \\
\hline$L C O E x[\mathrm{EUR} / \mathrm{MWh}]$ & levelized cost of exergy \\
\hline $\mathrm{LCOH}[\mathrm{EUR} / \mathrm{MWh}]$ & levelized cost of heating \\
\hline$\dot{m}[\mathrm{~kg} / \mathrm{s}]$ & mass flow rate \\
\hline$M W[\mathrm{~g} / \mathrm{mole}]$ & molecular weight \\
\hline$N P V[\mathrm{MEUR}]$ & net present value \\
\hline$N[\%]$ & availability factor \\
\hline$p_{e l}[\mathrm{EUR} / \mathrm{MWh}]$ & electricity price \\
\hline$p_{\text {heat }}[\mathrm{EUR} / \mathrm{MWh}]$ & heat price \\
\hline$p[\mathrm{bar}]$ & pressure \\
\hline$\dot{Q}[\mathrm{MW}]$ & heat \\
\hline$S I C[\mathrm{EUR} / \mathrm{kW}]$ & specific investment cost \\
\hline$s[\mathrm{~kJ} / \mathrm{kgK}]$ & specific entropy \\
\hline$T\left[{ }^{\circ} \mathrm{C}\right]$ & temperature \\
\hline$v[\mathrm{~m} / \mathrm{s}]$ & velocity \\
\hline$\dot{W}[\mathrm{MW}]$ & electrical power \\
\hline$x[-]$ & ratio of electrical to total energy \\
\hline$\eta[\%]$ & efficiency \\
\hline
\end{tabular}




\begin{tabular}{cc}
\hline symbol & description \\
\hline$b$ & brine \\
crit & critical point \\
en & electricity \\
env & energy \\
ex & environment \\
$f$ & exergy \\
$g$ & fan of the condenser \\
inj & injection state \\
$m$ & motor \\
min & minimum \\
net & net value \\
$p$ & pump \\
prod & production state \\
return & return of DH system \\
sup & degree of superheating \\
supply & supply of DH system \\
th & thermal \\
wf & working fluid \\
wells & well drillings \\
\hline
\end{tabular}

\section{References}

[1] D. Fiaschi, G. Manfrida, E. Rogai, L. Talluri, Exergoeconomic analysis and comparison between ORC and Kalina cycles to exploit low and medium-high temperature heat from two different geothermal sites, Energy Conversion and Management 154 (2017) 503-516.

[2] A. Aali, N. Pourmahmoud, V. Zare, Exergoeconomic analysis and multi-objective optimization of a novel combined flash-binary cycle for Sabalan geothermal power plant in Iran, Energy Conversion and Management 143 (2017) 377-390. 
[3] D. Walraven, B. Laenen, W. D'haeseleer, Minimizing the levelized cost of electricity production from low-temperature geothermal heat sources with ORCs: Water or air cooled?, Applied Energy 142 (2015) 144-153.

[4] M. Usman, M. Imran, Y. Yang, D. H. Lee, B.-S. Park, Thermo-economic comparison of aircooled and cooling tower based Organic Rankine Cycle (ORC) with R245fa and R1233zde as candidate working fluids for different geographical climate conditions, Energy 123 (2017) $353-366$.

[5] D. Budisulistyo, C. S. Wong, S. Krumdieck, Lifetime design strategy for binary geothermal plants considering degradation of geothermal resource productivity, Energy Conversion and Management 132 (2017) 1-13.

[6] C. Yilmaz, Thermoeconomic cost analysis and comparison of methodologies for Dora II binary geothermal power plant, Geothermics 75 (2018) 48-57.

[7] C. Clauser, M. Ewert, The renewables cost challenge: Levelized cost of geothermal electric energy compared to other sources of primary energy Review and case study, Renewable and Sustainable Energy Reviews 82 (2018) 3683-3693.

[8] T. T. Tran, A. D. Smith, Incorporating performance-based global sensitivity and uncertainty analysis into LCOE calculations for emerging renewable energy technologies, Applied Energy 216 (2018) 157-171.

[9] K. Braimakis, S. Karellas, Integrated thermoeconomic optimization of standard and regenerative ORC for different heat source types and capacities, Energy 121 (2017) 570-598.

[10] C. Zhang, C. Liu, S. Wang, X. Xu, Q. Li, Thermo-economic comparison of subcritical organic Rankine cycle based on different heat exchanger configurations, Energy 123 (2017) 728-741.

[11] H. Tian, L. Chang, Y. Gao, G. Shu, M. Zhao, N. Yan, Thermo-economic analysis of zeotropic mixtures based on siloxanes for engine waste heat recovery using a dual-loop organic Rankine cycle (DORC), Energy Conversion and Management 136 (2017) 11-26.

[12] H. Xi, M.-J. Li, Y.-L. He, Y.-W. Zhang, Economical evaluation and optimization of organic Rankine cycle with mixture working fluids using R245fa as flame retardant, Applied Thermal Engineering 113 (2017) 1056-1070. 
[13] D. F. Dominković, M. Wahlroos, S. Syri, A. S. Pedersen, Influence of different technologies on dynamic pricing in district heating systems: Comparative case studies, Energy 153 (2018) $136-148$.

[14] M. Huculak, W. Jarczewski, M. Dej, Economic aspects of the use of deep geothermal heat in district heating in Poland, Renewable and Sustainable Energy Reviews 49 (2015) 29-40.

[15] A. Keçeba, Energetic, exergetic, economic and environmental evaluations of geothermal district heating systems: An application, Energy Conversion and Management 65 (2013) 546-556.

[16] M. Mehrpooya, M. Ashouri, A. Mohammadi, Thermoeconomic analysis and optimization of a regenerative two-stage organic Rankine cycle coupled with liquefied natural gas and solar energy, Energy 126 (2017) 899-914.

[17] E. Akrami, A. Chitsaz, H. Nami, S. Mahmoudi, Energetic and exergoeconomic assessment of a multi-generation energy system based on indirect use of geothermal energy, Energy 124 (2017) 625-639.

[18] F. A. Boyaghchi, H. Safari, Parametric study and multi-criteria optimization of total exergetic and cost rates improvement potentials of a new geothermal based quadruple energy system, Energy Conversion and Management 137 (2017) 130-141.

[19] R. Leiva-Illanes, R. Escobar, J. M. Cardemil, D. C. Alarcón-Padilla, Comparison of the levelized cost and thermoeconomic methodologies Cost allocation in a solar polygeneration plant to produce power, desalted water, cooling and process heat, Energy Conversion and Management 168 (2018) 215-229.

[20] S. Karellas, K. Braimakis, Energyexergy analysis and economic investigation of a cogeneration and trigeneration ORCVCC hybrid system utilizing biomass fuel and solar power, Energy Conversion and Management 107 (2016) 103-113.

[21] E. A. Pina, M. A. Lozano, L. M. Serra, Allocation of economic costs in trigeneration systems at variable load conditions including renewable energy sources and thermal energy storage, Energy 151 (2018) 633-646. 
[22] A. S. Mundada, K. K. Shah, J. M. Pearce, Levelized cost of electricity for solar photovoltaic, battery and cogen hybrid systems, Renewable and Sustainable Energy Reviews 57 (2016) 692-703.

[23] A. M. Pantaleo, S. M. Camporeale, A. Miliozzi, V. Russo, N. Shah, C. N. Markides, Novel hybrid CSP-biomass CHP for flexible generation: Thermo-economic analysis and profitability assessment, Applied Energy 204 (2017) 994-1006.

[24] E. Martelli, F. Capra, S. Consonni, Numerical optimization of Combined Heat and Power Organic Rankine Cycles Part A: Design optimization, Energy 90 (2015) 310-328.

[25] M. Noussan, Allocation factors in Combined Heat and Power systems Comparison of different methods in real applications, Energy Conversion and Management 173 (2018) 516-526.

[26] D. Walraven, B. Laenen, W. D'haeseleer, Optimum configuration of shell-and-tube heat exchangers for the use in low-temperature organic Rankine cycles, Energy Conversion and Management 83 (2014) 177-187.

[27] S. Van Erdeweghe, J. Van Bael, B. Laenen, W. D'haeseleer, Design and off-design optimization procedure for low-temperature geothermal organic Rankine cycles (Working paper, submitted for publication), 2018. URL: https://www.mech.kuleuven.be/en/tme/research/ energy_environment/Pdf /wp-en-2018-13-3.pdf

[28] S. Bos, B. Laenen, Development of the first deep geothermal doublet in the Campine Basin of Belgium, European Geologist 43 (2017) 16-20.

[29] CREG, Prijs van elektriciteit en aardgas in België, in de 3 regio's en in de buurlanden, 2018. URL: https://www.creg.be/sites/default/files/assets/Prices/ BelEnergyPriceCompNL.pdf

[30] IRENA, Renewable energy in district heating and cooling - Case studies, 2017. URL: www. irena.org/remap.

[31] P. Garg, M. S. Orosz, P. Kumar, Thermo-economic evaluation of ORCs for various working fluids, Applied Thermal Engineering 109 (2016) 841-853. 
[32] J. Calm, G. Hourahan, Physical, Safety and Environmental Data for Current and Alternative Refrigerants, in: International Congress of Refrigeration, Prague,

Czech Republic, 2011. URL: http://www.hourahan.com/wp/wp-content/uploads/2010/08/ 2011-Physical-Safety-and-Environmental-Data2.pdf.

[33] S. Van Erdeweghe, J. Van Bael, B. Laenen, W. D'haeseleer, Optimal configuration for a lowtemperature geothermal CHP plant based on thermoeconomic optimization (Working paper, submitted for publication), 2018. URL: https://www.mech.kuleuven.be/en/tme/research/ energy_environment/Pdf/wp-en-2018-17.pdf

[34] IEA, Technology Roadmap - Geothermal Heat and Power, 2011. URL: https://www.iea.org/newsroomandevents/pressreleases/2011/june/

1. how-to-achieve-at-least-a-tenfold-increase-in-supply-of-geothermal-power-and-hea. html.

[35] European Commission, EU Reference Scenario 2016, 2014. URL: https://ec.europa.eu/ energy/sites/ener/files/documents/ref2016_report_final-web.pdf.

[36] F. Heberle, D. Brüggemann, Thermoeconomic Analysis of Hybrid Power Plant Concepts for Geothermal Combined Heat and Power Generation, Energies 7 (2014) 4482-4497. 